\title{
THE EFFECTS OF MULCH COVER ON SPLASH EROSION IN MAKURDI TOWN
}

S. A. IORKUA

(Received 11 October 2011; Revision Accepted 20 February 2012)

\begin{abstract}
Soil erosion has continued to be a serious environmental problem, particularly among the farming communities. In Benue State, the dominant economic activity is subsistence farming which is done under sub humid rainfall conditions. Splash erosion resulting from intense rainfall therefore poses severe problems that can be alienated through good soil management practices including mulching. This paper assessed the effects of mulch cover on splash erosion in Makurdi Town. Data was collected on splashed sediments in an experimental station in Benue State University, Makurdi for a period of one rainy season in 2007. Sediment collectors were attached to 5 soil trays placed at an angle of 5 degrees to collect the amount of splash yield at every rain event. One each of the 5 trays was covered with groundnut chafes, rice husk, grasses and soyabeans chafes with the last tray as control. The soils were oven dried and measured. The result of the splash yield shows that splash from bare surface is $\left(46.48 \mathrm{~kg} / \mathrm{m}^{2} / \mathrm{yr}\right)$ more than that from the four mulch treatments combined $\left(40.85 \mathrm{~kg} / \mathrm{m}^{2} / \mathrm{yr}\right)$. The effect of the various mulch materials used in checking splash was also compared. The result indicates that the differences between the mulched materials used in this study are not statistically significant. Local crop farmers in parts of Benue State can plant cover crop and mulch heaps during sowing season in addition to good tillage methods to check splash erosion.
\end{abstract}

KEYWORDS: Splash erosion, soil tray, mulch, sediments, urban centre

\section{$1.0 \quad$ INTRODUCTION}

Increased anthropogenic pressure on land resources has led to soil erosion and land degradation world wide, especially in the seasonally humid tropical areas including Benue state. The system of agriculture in these areas frequently leaves the land bare for varying lengths of time, leading to various types of water erosion, including rainsplash erosion and surface wash. The rainfall runoff usually does not have enough power to detach and entrain most soil particles; it therefore relies on rainsplash to detach such particles (Van Dijk, et al., 2003). However, it requires actual field measurement for real assessment and appreciation of the extent /intensity of splash erosion.

Mulching is the covering of a soil surface with either organic material such as cut grass, straw, leaves, stem, plant and domestic trash, with residues, dung, and sawdust, or inorganic materials like ash, sand, stones and opaque and transparent plastic (Thurston 1992, Lombin, 1999, Brady, 2000 and Brady and Weil, 2002). Mulching has tremendous potential as a method for splash erosion control (Morgan, 1986 and Cattan, Cabidoche, Lacas, and Voltz, 2006). For example, Oyegun (1980) and Salau (1989) have highlighted the importance of mulching to include protecting the soil from rainfall impact especially if there is reach 90 percent soil cover. According to them, mulching has effects on splash erosion and soil physical properties beside the other climatological effects.
According to Thurston (1992), soil mulch can be especially important in tropical areas with heavy rainfall, as it improves water absorption and reduces rain splashing.The use of mulches provide many agronomic benefits, including protecting soil against splash erosion. Considering the value of mulches for splash erosion control among others, there is therefore the need for more of these studies in Benue state where majority of the working population depend on arable agriculture for sustenance.

The effectiveness of mulch in reducing runoff and soil losses, however, depends on factors of rainfall erosivity, soil type and condition, steepness and length of slope, and the rate, position and type of mulch application (Foster, Johnson, and Mildenhaver, 1982). The use of gravel and sand as mulch to conserve the sporadic and limited rainfall for reliable crop production is a traditional technique of soil conservation that is still practiced in the Loess area of China (Xiao-Yan Li, 2003). There is also the largely undocumented traditional system among the people of Benue State that involves mulching land before making heaps and mulching the heaps before and after planting yam seedlings. The studies quoted above did not use natural rainfall neither were they specific to splash.

The aim of the study is to monitor splash erosion in the field with a view to determine the effects of mulch on splash erosion in the humid tropical area of Makurdi town. The study covered one rain season (April - October of 2007) covering 59 rainfall events for which splash erosion

S. A. Iorkua, Department of Geography, Benue State University, Makurdi, Nigeria. 
was measured and used for the study.

\subsection{Materials and Methods}

\subsection{Study Area}

This study is carried out in the Geography Department Agro-Meteorological Station, located at the western part of the Benue State University on lat. $7^{\circ} 43^{\prime}$ $44^{\prime \prime} \mathrm{N}$ and long. $8^{\circ} 33^{\prime} 31^{\prime \prime}$ at $91 \mathrm{~m}$ asl (Fig. 1) The geological formation of the study area is comprised of the cretaceous sediments, made up of false-bedded sandstones and poorly sorted thick unconsolidated sandstones. The soils of the area are Typic Haplustuit and Orthic Acrisol. Temperatures are high throughout the year, averaging $27^{\circ} \mathrm{C}$ to $31^{\circ} \mathrm{C}$, though it may occasionally rise to $37^{\circ} \mathrm{C}$ in March and April. Annual rainfall total is between $900 \mathrm{~mm}$ and $1500 \mathrm{~mm}$. The majority of the rural population around the study area engages in crop production as means of livelihood. Land is therefore intensively put under intense use and exposed to splash erosion with little or less mulch cover, especially after harvesting.

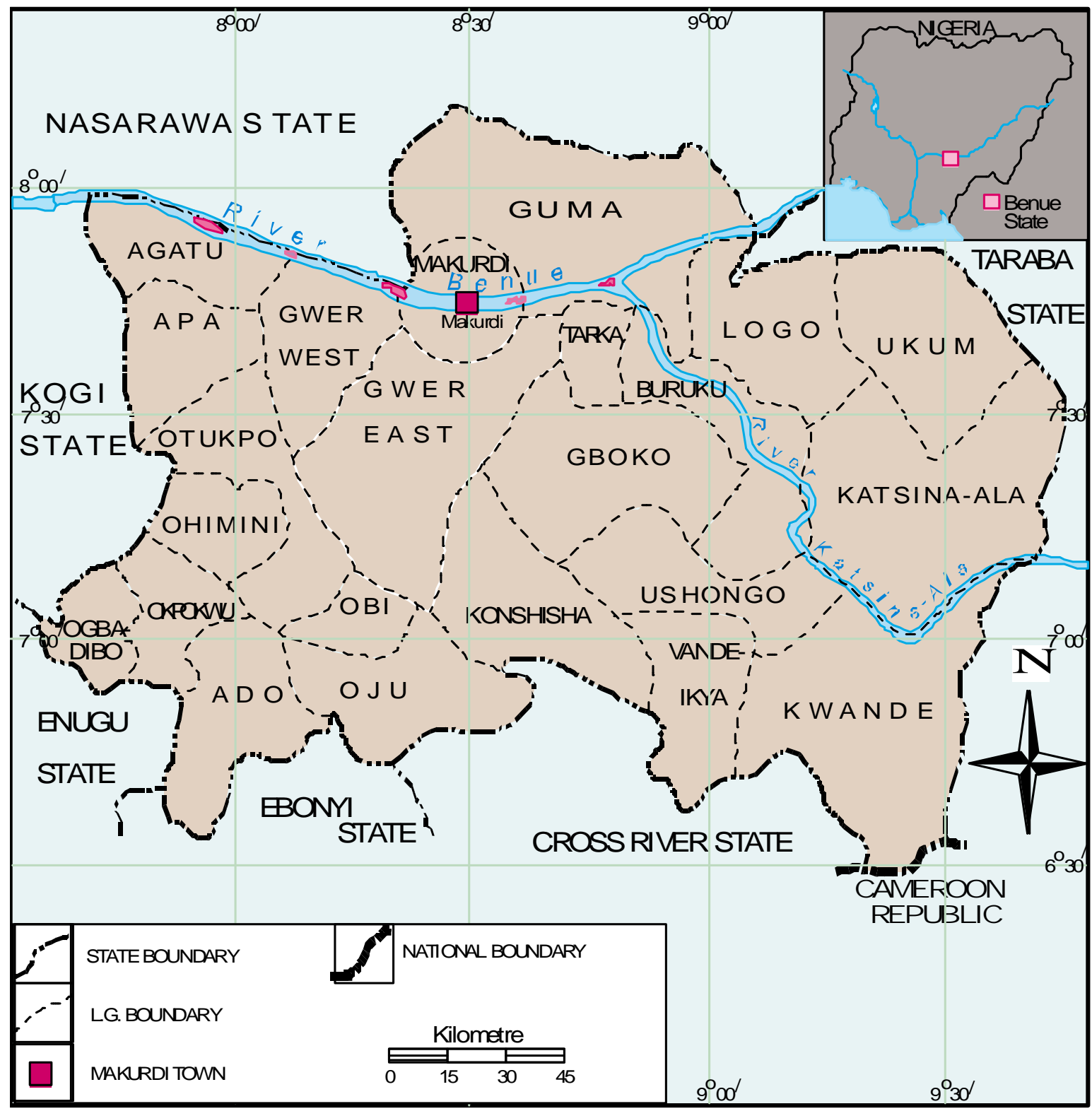

Fig.1. Benue State showing Makurdi town Source: Benue State Ministry of Lands and Survey, 2003

Study methodology comprise of 5 soil trays of galvanized metal, with dimensions of $0.60 \mathrm{~m} \times 0.30 \mathrm{~m} \times$ $0.10 \mathrm{~m}$. One each detachable splash collectors were placed by the sides of the 5 soil trays using $1.27 \mathrm{~cm}$ flat rods attached to the bottom of the soil tray. The soil tray was placed on a wooden table measuring $70 \mathrm{~cm}$ by $40 \mathrm{~cm}$ and $20 \mathrm{~cm}$. The slope angles (5 degrees) of the soil trays were fixed with the aid of two adjustable support rods attached to the bottom of the soil tray and the wooden table. 


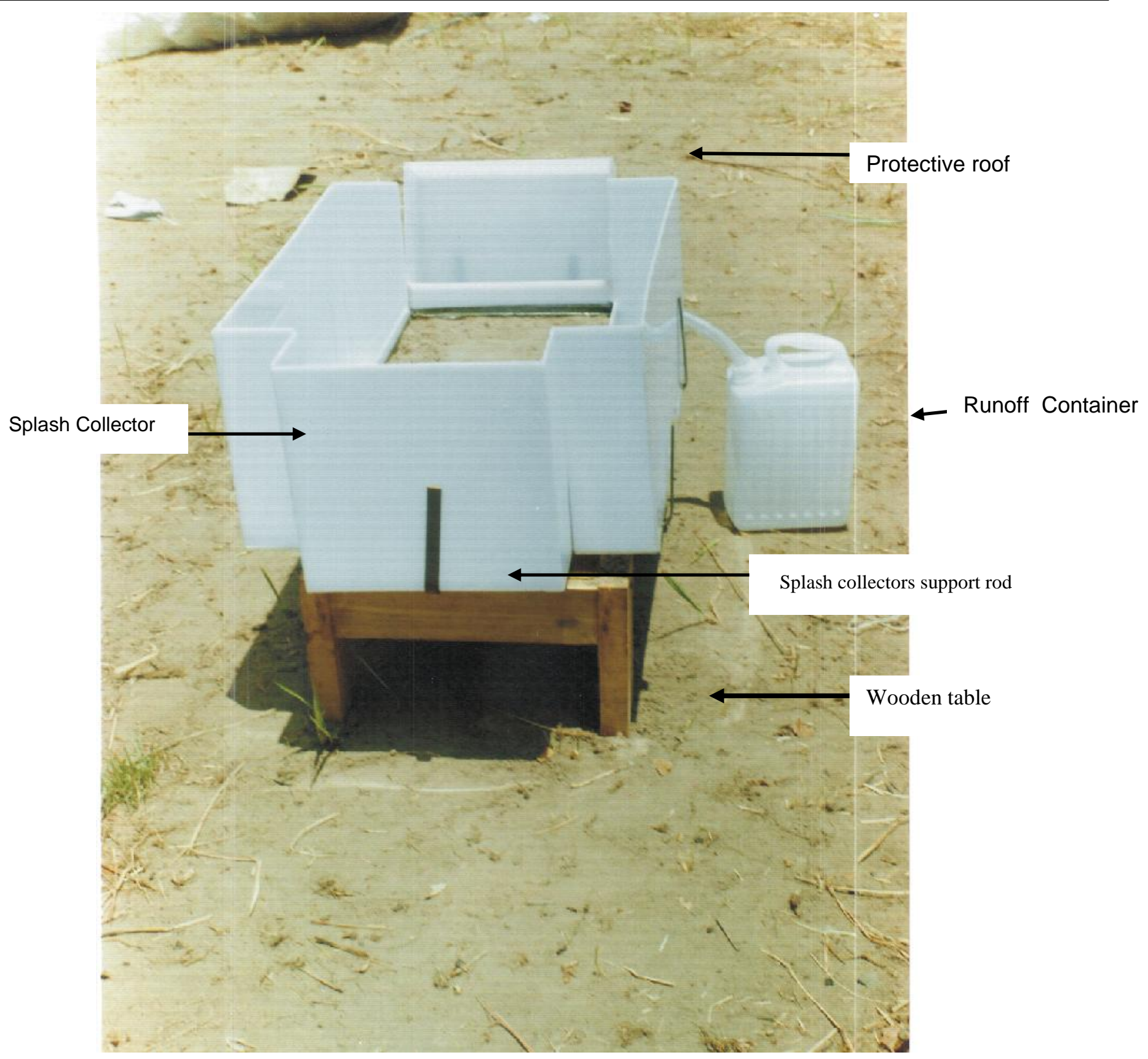

Plate 1. A typical soil tray used in the study

Further, upslope, lateral and downslope splash collectors, constructed out of $3 \mathrm{~mm}$ plastics, were attached to the soil trays in a vertical position. The lateral splash collectors have dimensions of $60 \mathrm{~cm}$ by $30 \mathrm{~cm}$ by $10 \mathrm{~cm}$ and $10 \mathrm{~cm}$. The upslope and downslope splash collectors have dimensions of $30 \mathrm{~cm}$ by $30 \mathrm{~cm}$ by $10 \mathrm{~cm}$ by $10 \mathrm{~cm}$. The splash collectors are used to assess the distribution of splashed sediments, though that aspect was not studied independently in this study. Rainfall was measured during the research with Wired Rain Meter.

Five soil trays, each with four splash collectors (of 2 laterals, 1 each of downslope and upslope) (See plate 1) were used in this study to monitor the effects of mulch on components of splash. A $4 \mathrm{~cm}$ thick layer of coarse (8-
$30 \mathrm{~cm}$ ) gravel was placed at the bottom of each soil tray to facilitate drainage through holes at the downslope end of the tray. A wet piece of cloth was placed on the gravel and the tray was filled with soil to the apron and up to $2-3 \mathrm{~mm}$ below the rims of the splash collectors. The experiment was set during the dry season and the soil was neither sieved nor wetted before use. The initial moisture content, aggregation and the other soil properties were determined before the commencement of measurements. Some soil material was added in June and September to maintain the regular soil level.

The 5 trays were used with one serving as control that is, without mulch cover. The other 4 were mulched with groundnut and soyabean chafes, rice husk and grass 
residues, which are readily available in the area to the farmers. After every rainfall event, the splash produced was measured from each soil tray. The measurements from upslope, downslope and the two lateral sides of a tray combined to produce one measurement unit per rain event. The splashed sediment were transferred after each rain event into stainless plates of $14 \mathrm{~cm}^{3}$, and oven dried at a temperature of $105^{\circ} \mathrm{C}$ for 24 hours in a mechanical oven before measurement. Fifty-nine rain events were measured. The weight of the oven dried soil material splashed was measured for each rainstorm event with a digital weighing machine. Tables and percentages are used to analyze the data collected.

\subsection{RESULTS AND DISCUSSION}

The data collected on the splashed sediments (April to October, 2007) is summarized and presented in Table 1 . The result shows that there is generally more splash at the beginning of the rains from April up to June. However, the mulched trays recorded far less sediments than the control. For example just $28.02 \%$ of the sediments at control splashed at the mulch with grass.

The effect of cover (mulch) on splash is glaring as shown by Table 1. The result of the analysis as displayed in Table 1 showed that splash from bare surface is more than the quantity from the four mulch treatments combined. Splash from bare surface (control) amounted to $46.48 \mathrm{~kg} / \mathrm{m}^{2} / \mathrm{yr}$. On the other hand, the 4 mulched surfaces combined recorded just $40.85 \mathrm{~kg} / \mathrm{m}^{2} / \mathrm{yr}$. The effect of the various mulch materials used in checking splash was also compared using the amount of sediments collected under each mulch. The result indicates that the differences between the mulched materials used in this study are not statistically significant. The result of the present study agrees with the work of Oyegun, (1980), Salau, (1989), and Thurston, (1002).

Table 1: Monthly and total splash in grams from different mulch treatments and control

\begin{tabular}{|l|l|l|l|l|l|l|}
\hline Months & Control & Groundnut & Grass & Rice & Soyabeans & $\begin{array}{l}\text { Monthly } \\
\text { Total }\end{array}$ \\
\hline April & 238.68 & 58.26 & 66.88 & 56.08 & 50.10 & 470.00 \\
\hline May & 168.54 & 40.53 & 34.84 & 33.80 & 27.43 & 305.14 \\
\hline June & 255.85 & 61.93 & 53.17 & 49.89 & 46.03 & 466.87 \\
\hline July & 104.66 & 15.43 & 17.46 & 9.55 & 13.23 & 168.33 \\
\hline August & 127.17 & 34.98 & 47.73 & 51.46 & 30.40 & 291.74 \\
\hline September & 128.19 & 72.21 & 70.98 & 40.75 & 36.98 & 439.11 \\
\hline October & 36.43 & 19.34 & 18.80 & 13.20 & 12.64 & 100.41 \\
\hline $\begin{array}{l}\text { Annual } \\
\text { Total }\end{array}$ & 1059.52 & 302.68 & 309.86 & 254.73 & 216.81 & 2241.60 \\
\hline
\end{tabular}

Source: Fieldwork 2007

\subsection{CONCLUSION}

Gross splash was high for the soil tray without mulch cover. The implication of this finding is that splash contributes significantly to the volume of soil in runoff, apart from causing erosion on its own. This is because splashed sediments are not only transported by runoff, they also aid in removing more sediments by enhancing friction in runoff. The increased volume of soil in runoff causes the silting up of streams, dams and canals.

This emphasizes the importance of the study of splash erosion with a view to creating conditions that inhibits the initiating process of soil erosion. Furthermore, this finding shows that mulching is an effective way of reducing splash erosion in the study area and should therefore be encouraged. This practice is relatively cheap as plant residues to be used for this is usually discarded and can be sourced locally. This finding that splash is higher at onset of rain is also important for erosion control in this area. The beginning of the rainy season is the period when planting commences and the crops are yet to produce enough leaves to cover the land and protect it against rain splash. Thus farmers do not have to burn the weeds generated during the land preparation time so that it can be used as mulch at planting time. There is no significant difference in the effect of the type of mulch material used on splash rates. In other words, the four mulch types reduced splash almost uniformly. The implication of this finding is that farmers can use any of the residues that are available locally. This is important because not all the crops used are produced everywhere. The system of land management by local farmers in most parts of Benue State by planting land covering crops, mulching of yam heaps during sowing season and tillage methods are practical ways of partly checking erosion. This system is highly recommended to the farmers.

\section{REFERENCES}

Adeoye, K. B., 1984. Influence of grass mulch on soil temperature, soil moisture and yield of maize and gero millet in a savanna zone soil. Savanna Journal of Agricultural Research, 2, 87-97.

Brady, N .C., 2000. The Nature and Properties of Soil, $10^{\text {th }}$ Edition, Prentice- Hall of India, New Delhi. 
Brady, N .C and Weil, R. R., 2002. The Nature and Properties of Soil, $13^{\text {th }}$ Edition, Prentice-Hall of India

Cattan, P., Cabidoche, Y. M., Lacas, J. G and Voltz, M., 2006. Effects of tillage and Mulching on runoff under Banana (Musa Spp.) on a tropical Andisol. Soil and Tillage Research 86, (1): 38-51.

De Vleeschauwer, D. J., Lal, R. J and Malata, R., 1980. Effects of amount of Surface Mulch on Physical and Cervical Properties of an Alfisol from Nigeria, Journal of Science of food and Agriculture, 31, 730-738.

Foster, G. R., Johnson, C. B and Midenhaver, W. C., 1982. Hydraulics of Failure of un-anchored Com Stalk and Wheat Straw Mulches for Erosion Control. Trans ASEA, (25): 940-946.

Lal, R., 1993b. Technological Options towards Sustainable agriculture for different Ecological regions of Sub-Saharan Africa. In Rayland, Lal, R.Ed., Technologies For sustainable agriculture in the tropics. American Society of Agronomy, Madison, W, USA Special Publication (56): 295308.

Lombin, G., 1999: Soil Science, In, A. Youdewei, F.o.C. Ezeidinma, and O.C. Onazi (eds.) Introduction to Tropical agriculture. Longman Group Ltd. Nigeria.

Morgan, R. P. C., 1986. Soil Erosion and Conservation. Longman Scientific and Technical. Burnt Mile, Harlow, U.K. 298p.

Oyegun, G. E., 1980. The Effects of Tropical Rainfall on Sediments Yield from different Landuse Surface in Sub-urban Ibadan; Ph.D. Thesis, Univ. of Ibadan.
Poesen, J. W. A.,. Ingelme-Sanchez, F and Mucher, H., 1990. The Hydrological Response of Soil Surface to Rainfall as affected by Cover and Position of Rock Fragments in the Top Layer. Earth Surface Process, Landf. (15): 653-571.

Poesen, J., 1986. Field Measurement of Splash Erosion to Validate a Splash Transport Model. Z. Geomorp. N.P., Suppl. Bd., (58): 81-91.

Poesen, I. W. A and Lavee, H., 1990. Effects of size and Incorporation of synthetic Mulch on Runoff and Sediment Yield from Interrils in a Laboratory Study with Simulated Rainfall, Soil \& Tillage Research, (21): 209-223.

Van Dijk., A. I. J. M., Bruijnzeel, L. A. and Eisma, L. C. C. H., 2003. A Methodology to Study Rain splash and Wash Processes under Natural rainfall. Hydrological Processes (17): 153-167.

Salau, O., 1989. Comparative Analysis of Microclimatic Conditions in plantain Plantations with different types of mulch, Ph. D. Thesis Univ of Ibadan

Thurston, H. D., 1992. Sustainable Practices for plant Disease management in Traditional farming systems. Western Boulder, CO.

Xiao-Yan Li., 2003. Graved- Sand mulch for Soil and water conservation in the semiarid Loess region of northwest Cluna. Catena, 52. 105-127. 